\title{
Pre-processed caspase-9 contained in mitochondria participates in apoptosis
}

\author{
P Costantini ${ }^{1}$, J-M Bruey ${ }^{2}$, M Castedo ${ }^{1}$, D Métivier ${ }^{1}$, \\ M Loeffler ${ }^{1}$, SA Susin ${ }^{1}$, L Ravagnan ${ }^{1}$, N Zamzami ${ }^{1}$, C Garrido ${ }^{2}$ \\ and Guido Kroemer*, \\ ${ }^{1}$ Centre National de la Recherche Scientifique, UMR1599, Institut Gustave \\ Roussy, 39 rue Camille-Desmoulins, F-94805 Villejuif, France \\ 2 INSERM Unité 517, 7 Boulevard Jeanne d'Arc, Faculty of Medicine, F-21033 \\ Dijon, France \\ * Corresponding author: G Kroemer CNRS-UMR1599, Institut Gustave Roussy, \\ Pavillon de Recherche 1, 39 rue Camille-Desmoulins, F-94805 Villejuif, France. \\ Tel. 33-1-42 1160 46; Fax 33-1-42 1160 47; E-mail: kroemer@igr.fr
}

Received 16.3.01; revised 11.6.01; accepted 12.7.01

Edited by SJ Martin

\begin{abstract}
As shown here, mitochondria purified from different organs (liver, brain, kidney, spleen and heart) contain both procaspase- 9 and the processed, mature form of caspase- 9 . Purified liver mitochondria release mature caspase- 9 upon induction of permeability transition in vitro. This is accompanied by a discrete increase in the enzymatic cleavage of pro-caspase-9 substrates. We found that SHEP neuroblastoma cells constitutively contain pre-processed caspase-9 in their mitochondria, using a combination of subcellular fractionation and immunofluorescence with an antibody specific for the processed caspase. This is a cell type-specific phenomenon since HeLa cells mitochondria mainly contain pro-caspase-9 and comparatively little processed caspase-9. Upon introduction of apoptosis, mitochondrial pro-caspase-9 translocates to the cytosol and to the nucleus. This phenomenon is inhibited by transfection with Bcl-2. In synthesis, we report the unexpected finding that mitochondria can contain a preprocessed caspase isoform in non-apoptotic cells. Bcl-2mediated regulation of mitochondrial membrane permeabilization may contribute to apoptosis control by preventing mitochondrial, pre-processed caspase-9 from interacting with its cytosolic activators. Cell Death and Differentiation (2002) 9, 82-88. DOI: 10.1038/sj/cdd/4400932
\end{abstract}

Keywords: Apoptosis; Bcl-2; caspase-9; mitochondria; permeability transition

Abbreviations: AIF, apoptosis-inducing factor; Apaf-1, apoptosis protease activating factor; CsA, cyclosporin A; Cyt c, cytochrome $c$; $\mathrm{Hsp60}$, heat shock protein 60; PT, permeability transition; $t$-BHP, tert-butyhlhydroperoxide

\section{Introduction}

Caspases are synthesized as enzymatically inactive (or poorly active) precursor proteins and are activated by proteolytical (auto)-processing, yielding active tetraheteromers containing two large and two small subunits. ${ }^{1}$ Caspases fulfill a dual role in apoptosis. On the one hand, they are activated in response to pro-apoptotic signals or cellular damage via and indirect mechanism. As a result of mitochondrial membrane permeabilization, which may set the point-of-no-return of the death process, ${ }^{2,3}$ caspase activators are released from the mitochondrial intermembrane space. Such activators include cytochrome $c$ (which triggers the assembly of the cytochrome c/Apaf-A/pro-caspase- 9 activation complex, the apoptosome), ${ }^{4,5}$ heat shock protein 10 (which favors apoptosome activation), ${ }^{6}$ and Smac/DIABLO (which inactivates caspase-inhibitory IAPs). ${ }^{7,8}$ In this scenario, caspase activation is required for the full manifestation of the apoptotic phenotype (such as advanced chromatin condensation or oligonucleosomal DNA fragmentation) but is dispensable for cell death to occur. On the other hand, caspases may serve as signal transducing molecules which are rate-limiting for the transmission of an apoptogenic signal. This applies, for instance, to pro-caspase 8 which is recruited to the death-inducing signaling complex formed in proximity to oligomerized CD95 or TRAIL receptors, after their ligation. $^{9-11}$ Inactivation or inhibition of signal-transducing caspases abolishes cell death induction via the specific pathway they are involved in.

It is generally assumed that pro-caspases reside in the cytosol of cells. Intriguingly, at least in some cell types, procaspases are contained in defined subcellular compartments, suggesting that they are subject to local activation processes. Thus, caspase- 2 has been found to be enriched in the Golgi apparatus. ${ }^{12}$ Caspase-12 is confined to the endoplasmic reticulum and participates in the sensing of local stress. ${ }^{13}$ Moreover, pro-caspase $2,{ }^{14}$ pro-caspase- $3,{ }^{15}$ pro-caspase- $8,{ }^{16}$ and/or pro-caspase- $9,{ }^{14,17}$ depending on the cell type, have been found to be particularly abundant in the mitochondrial intermembrane space. This implies that, upon apoptotic permeabilization of the outer mitochondrial membrane, such pro-caspases are released into the cytosol where their activation is either achieved through the apoptosome (the case of pro-caspases- 9 and -3$)^{5}$ or via unknown mechanisms (the case of pro-caspase-2 and -8). The fact that pro-caspases may be secluded behind the outer membrane of mitochondria underlines the importance of mitochondrial membrane permeabilization as a ratelimiting step of the apoptotic cascade. Indeed, it appears that the anti-apoptotic members of the Bcl-2 family exert their cytoprotective action via a general stabilization of mitochondrial membranes, ${ }^{18}$ the mechanism of which is still unknown. 
Caspase-9 appears to be a functionally important initiator of the apoptotic cascade. In contrast to other caspases, the unprocessed form of caspase- 9 is enzymatically active, and processing itself increases its activity by only a factor of $\sim 10$. Pro-caspase- 9 and processed caspase- 9 are only active in the presence of their co-activators (namely the Apaf-1/Cytochrome $c$ complex). ${ }^{19}$ Invalidation of the caspase-9 gene ${ }^{20-22}$ and transfection with dominant-negative mutants of caspase$9^{23-25}$ have revealed its critical implication in developmental cell death (in particular in neurons), ${ }^{20}$ as well as in chemotherapy responses in vitro. ${ }^{22-25}$ In particular, in the mitochondrial pathway of cell death induction, caspase-9 appears to be necessary for full-blown apoptosis to occur. ${ }^{20,21}$

Here we report the unexpected finding that processed caspase- 9 may be constitutively enriched in mitochondria. Upon in vitro permeabilization of the outer mitochondrial membrane processed caspase- 9 is released from mitochondria, while increasing its enzymatic activity. In a neuroblastoma cell line, apoptosis induction is linked to the translocation of pre-processed caspase- 9 from mitochondria to the cytosol and to nuclei. Bcl-2 prevents this translocation. Our data suggest that loss of compartimentalization of caspase-9 may contribute to the apoptotic process.

\section{Results and Discussion}

\section{Pre-processed caspase-9 in mitochondria from primary cells}

A monoclonal antibody specific for the $\mathrm{N}$-terminus of caspase-9 recognized two proteins in extracts of highly purified mitochondria from different organs (liver, brain, kidney, spleen and heart) (not shown). These proteins correspond to unprocessed pro-caspase- 9 (46 kDa), as well as to the large subunit of processed, mature caspase-9 (35 kDa), suggesting that mitochondria contain pre-processed active caspase-9. Accordingly, a polyclonal antibody which recognizes the C-terminus of the $35 \mathrm{kDa}$ fragment of processed caspase- 9 , a neo-epitope created by cleavage of the precursor, detected a $\sim 35 \mathrm{kDa}$ band in immunoblots of purified mouse liver mitochondria (not shown), which are barely contaminated by ER and contain little if any lysosomal contamination. ${ }^{26}$ Purified liver mitochondria exposed to the pro-oxidant tert-butylhydroperoxide $(t$-BHP) underwent large amplitude swelling indicative of permeability transition (PT) (Figure 1B) and simultaneously released processed caspase- 9 , as well as the intermembrane proteins AIF and Cyt-C into the supernatant (Figure 1C). Cyclosporin A, a PT pore inhibitor, largely prevented the $t$-BHP-induced swelling, as well as the release of processed caspase-9, AIF, and Cyt-c (Figure 1B,C). Interestingly, only cleaved, mature caspase- 9 is released and no trace of the unprocessed protein is found in the supernatant. On the other hand, a very little amount of procaspase- 9 can be detected in the pellet (not shown), suggesting a processing of the immature protein upon induction of PT.
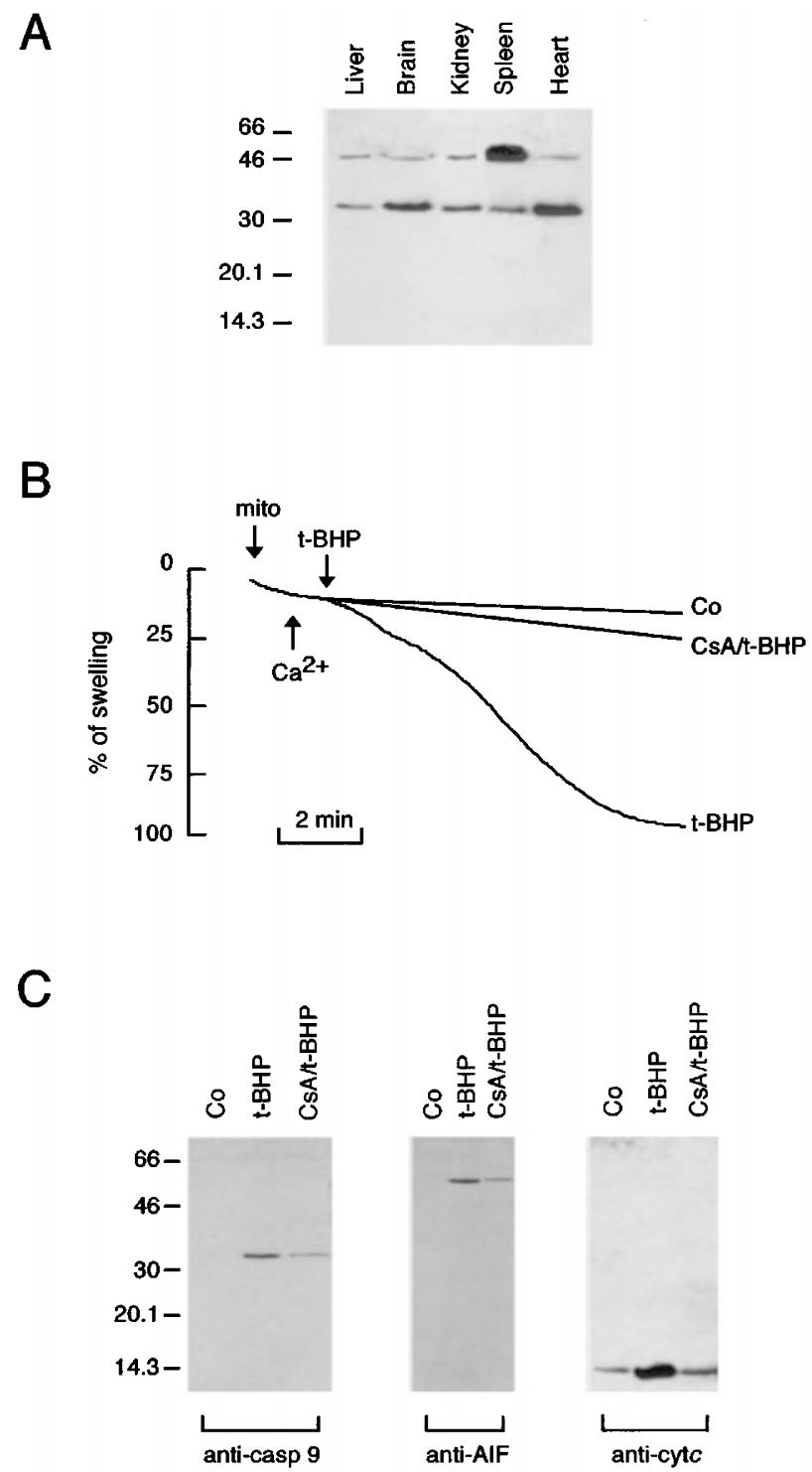

Figure 1 Identification of a mitochondrial pre-processed caspase-9. (A) Pre-processed caspase- 9 in mitochondria from different organs. Mitochondria were purified on a Percoll ${ }^{\mathbb{R}}$ gradient and subjected to SDS-PAGE $(100 \mu \mathrm{g} /$ lane $)$ and immunoblotting with an anti-caspase-9 monoclonal antibody which recognizes both the unprocessed $(46 \mathrm{kDa})$ and the cleaved caspase-9 $(35 \mathrm{kDa})$. (B) Large amplitude swelling of mitochondria. $1 \mathrm{mg}$ of liver mitochondria was incubated at room temperature in $1 \mathrm{ml}$ of swelling buffer. All the experiments were started with the addition under stirring of mitochondria, followed after $1 \mathrm{~min}$ by $10 \mu \mathrm{M} \mathrm{Ca}^{2+}$ (which by itself does not induce mitochondrial swelling), in the absence or in the presence of $1 \mu \mathrm{M}$ cyclosporin A (CsA). Where indicated by the arrow, $100 \mu \mathrm{M}$ t-BHP was added. After completion of the permeability transition, mitochondria were sedimented by centrifugation $\left(10 \mathrm{~min}, 10000 \times \mathrm{g}, 4^{\circ} \mathrm{C}\right)$, and the supernatant was subjected overnight to precipitation with 4 volumes of cold aceton. (C) Detection of processed caspase- 9 in the supernatant of mitochondria. Proteins contained in the supernatant of mitochondria (see description of panel B) were subjected to SDS-PAGE and immunoblotting with anticaspase-9, anti-AIF, and anti-cytochrome $c$ antibodies. Note that the anticytochrome $c$ blot has been overexposed 
A

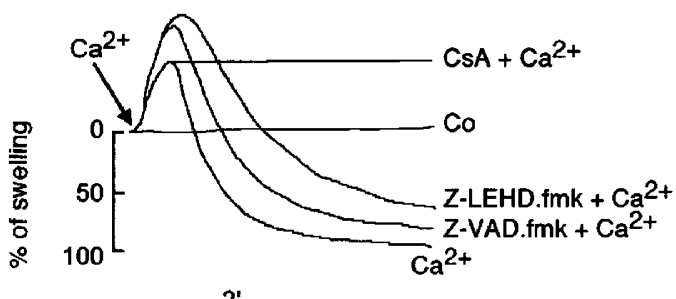

B

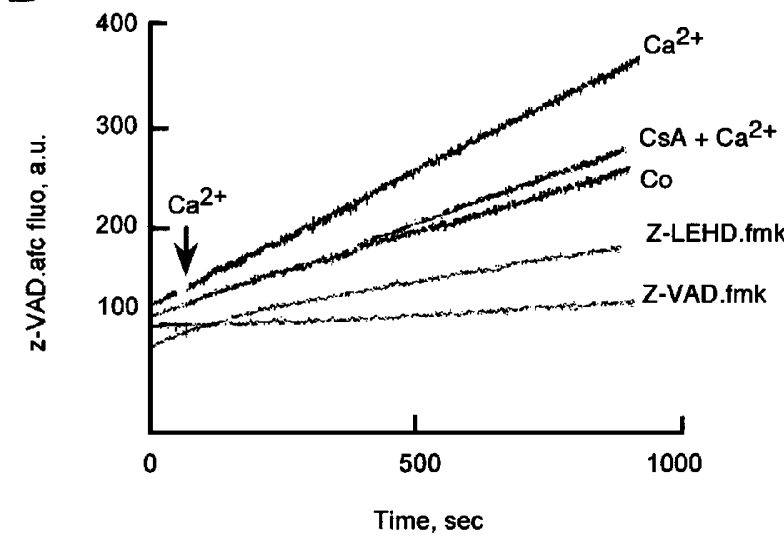

C

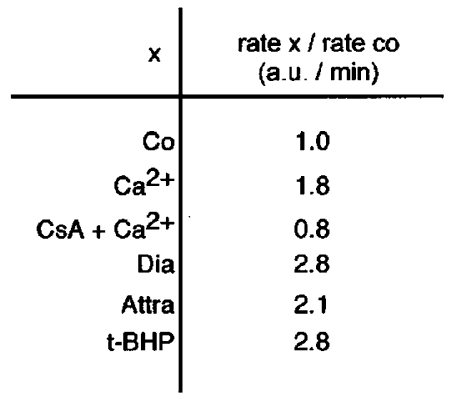

D

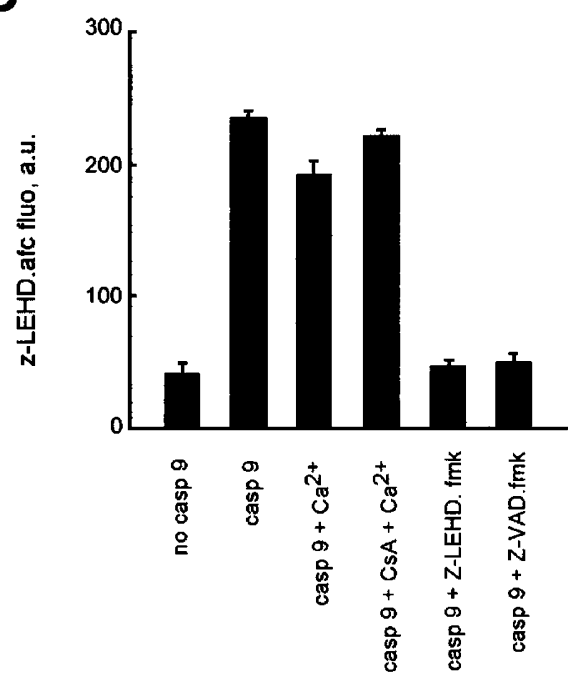

E

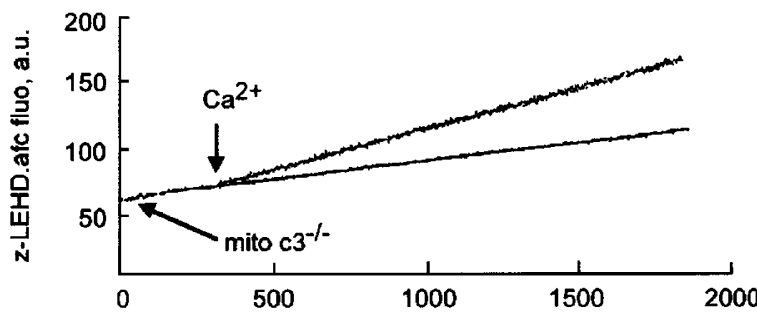

Time, sec

Figure 2 Caspase-9 activity in intact mitochondria. (A) Effect of caspase inhibitor on MPT. $0.5 \mathrm{mg}$ of liver mitochondria were incubated in $2 \mathrm{ml}$ of swelling buffer. After exactly $1 \mathrm{~min}, 200 \mu \mathrm{M} \mathrm{Ca}^{2+}$ was added in the absence or in the presence of the following inhibitors: cyclosporin $\mathrm{A}$ ( $1 \mu \mathrm{M}$, $1 \mathrm{~min}$ of preincubation) Z-VAD.fmk (100 $\mu \mathrm{M}, 15 \mathrm{~min}$ of pre-incubation) or Z-LEHD.fmk (100 $\mu \mathrm{M}, 15 \mathrm{~min}$ of pre-incubation), while monitoring large amplitude swelling. (B) Increased caspase-9 activity after MPT. Exactly under the same conditions described in (A), 0.25 mg of liver mitochondria were incubated in $0.2 \mathrm{ml}$ of swelling buffer with $100 \mu \mathrm{M}$ Z-VAD.afc and the Z-VAD.afc-cleaving activity was monitored continuously as fluorescence emission at $490 \mathrm{~nm}$ (excitation: $400 \mathrm{~nm}$ ). (C) Effect of MPT-opening agents $\left(200 \mu \mathrm{M} \mathrm{Ca}^{2+}, 1 \mu \mathrm{M} \mathrm{CsA}+200 \mu \mathrm{M} \mathrm{Ca}^{2+}+50 \mu \mathrm{M}_{\text {diamide, }} 10 \mu \mathrm{M} \mathrm{Ca}{ }^{2+}+5 \mathrm{mM}\right.$ atractyloside, $10 \mu \mathrm{M} \mathrm{Ca}{ }^{2+}+100 \mu \mathrm{M}$ tert-butylhydroperoxide) on the Z-VAD.afc-cleaving activity. The slope of the curves obtained as in B was determined and experimental values obtained $5 \mathrm{~min}$ after addition of the indicated agent were divided by the slope before their addition. Control experiments revealed that mitochondria did swell in response to high-dose $\mathrm{Ca}^{2+}$ alone (but not when CsA was added before, see Figure 1a), and did also swell with diamide, atractyloside and tert-butylhydroperoxide (not shown). (D) Effect of $\mathrm{Ca}^{2+}$ on the enzymatic activity of recombinant caspase-9. Five units of caspase-9 were incubated 30 min at $37^{\circ} \mathrm{C}$ with $100 \mu \mathrm{M}$ Z-LEHD.afc in a buffer containing $0.25 \mathrm{M}$ saccharose, $20 \mathrm{mM}$ Hepes-NaOH pH 6, $10 \mathrm{mM} \mathrm{NaCl}, 1.5 \mathrm{mM} \mathrm{MgCl}{ }^{2}$ and $1 \mathrm{mM}$ DTT, in the absence or in the presence of $200 \mu \mathrm{M} \mathrm{Ca}{ }^{2+}, 1 \mathrm{mM}$ cyclosporin A, $100 \mu \mathrm{M}$ Z-VAD.fmk (15 min of pre-incubation) or $100 \mu \mathrm{M}$ Z-LEHD.fmk (15 min of pre-incubation). Z-LEHD.afccleaving activity was followed as fluorescence emission at $490 \mathrm{~nm}$ (excitation: $400 \mathrm{~nm}$ ). (E) Activation of caspase-9 activity in mitochondria from caspase-3 ${ }^{-1}$ cells. $0.25 \mathrm{mg}$ of mitochondria purified from caspase- $3^{-1-}$ MEFs cells were incubated in $0.2 \mathrm{ml}$ of swelling buffer with $100 \mu \mathrm{M}$ Z-LEHD.afc, and the Z-LEHD.afccleaving activity was determined continuously 


\section{Permeability transition enhances caspase-9 activity}

Addition of $\mathrm{Ca}^{2+}$ to purified liver mitochondria causes mitochondrial swelling which is not affected by the pancaspase inhibitor Z-VAD.fmk nor the caspase-9-specific inhibitor Z-LEHD.fmk (Figure 2A). When mitochondria were subjected to a continuous measurement of caspase cleavage activity using the fluorogenic substrates Z-VAD.afc (Figure 2B) or Z-LEHD.afc (not shown), significant baseline activity was observed, and this activity was fully inhibited by Z-VAD.fmk or Z-LEHD.fmk (Figure 2B). Addition of $200 \mu \mathrm{M}$ $\mathrm{Ca}^{2+}$ (Figure 2B) alone to purified mitochondria led to a nearto-instantaneous ( $<10 \mathrm{~s}$ ) increase in caspase activity, by a factor of approximately two. Similar results were obtained when $10 \mu \mathrm{M} \mathrm{Ca}{ }^{2+}$ (which by itself does not induce mitochondrial swelling) plus diamide, atractyloside or $t$ BHP, which all cause large amplitude swelling (not shown), where added to mitochondria (Figure 2C). Pretreatment of mitochondria with $\mathrm{CsA}$ prevented the $\mathrm{Ca}^{2+}$-triggered increase in caspase activity, suggesting that it involved opening of the PT pore (Figure 2B,C). In a control experiment, neither $\mathrm{Ca}^{2+}$ nor $\mathrm{CsA}$ did modulate the activity of recombinant caspase-9 (Figure 2D). Thus, $\mathrm{Ca}^{2+}$ enhanced the caspase- 9 activity contained in or released from mitochondria via an indirect effect involving the PT pore. Mitochondria purified from caspase- $3^{-1-}$ mouse embryo fibroblasts also displayed an increase in the Z-LEHD.afccleaving activity (Figure 2E).

\section{Bcl-2-inhibited translocation of pre-processed caspase-9 from mitochondria in SHEP cells}

An antiserum which only recognizes processed caspase-9 but not its pro-form revealed a punctate cytoplasmic staining in healthy SHEP neuroblastoma cells. This immunoreactivity co-localized with the mitochondrial marker hsp60 (Figure 3A). Accordingly, purified mitochondria but not the cytosol from SHEP cells, subjected to Western blot analysis, contained a $35 \mathrm{kDa}$ fragment reacting with a caspase-9-specific antibody (Figure 3C). In contrast to SHEP cells, HeLa cells virtually lack processed caspase-9 detectable by immunofluorescence (Figure 3B) and HeLa mitochondria contained very little processed caspase-9, as determined by immunoblotting (Figure $3 \mathrm{C}$ ). After induction of apoptosis with staurosporin, active caspase- 9 became detectable in the cytosol (non-mitochondrial cytoplasm), as well as in the nucleus, both in SHEP cells and in HeLa cells (Figure 3A,B). Transfection-induced expression of $\mathrm{Bcl}-2$ in SHEP cells did not affect the mitochondrial (punctate) localization of active caspase-9 (Figure 4). However, Bcl-2 did prevent the staurosporin-induced translocation of both mitochondrial and cytosolic active caspase- 9 to the nucleus and simultaneously prevented chromatin condensation (Figure 4).

\section{Concluding remarks}

It has been assumed that procaspase-9 mainly resides in the cytosol of healthy cells. Upon induction of apoptosis,
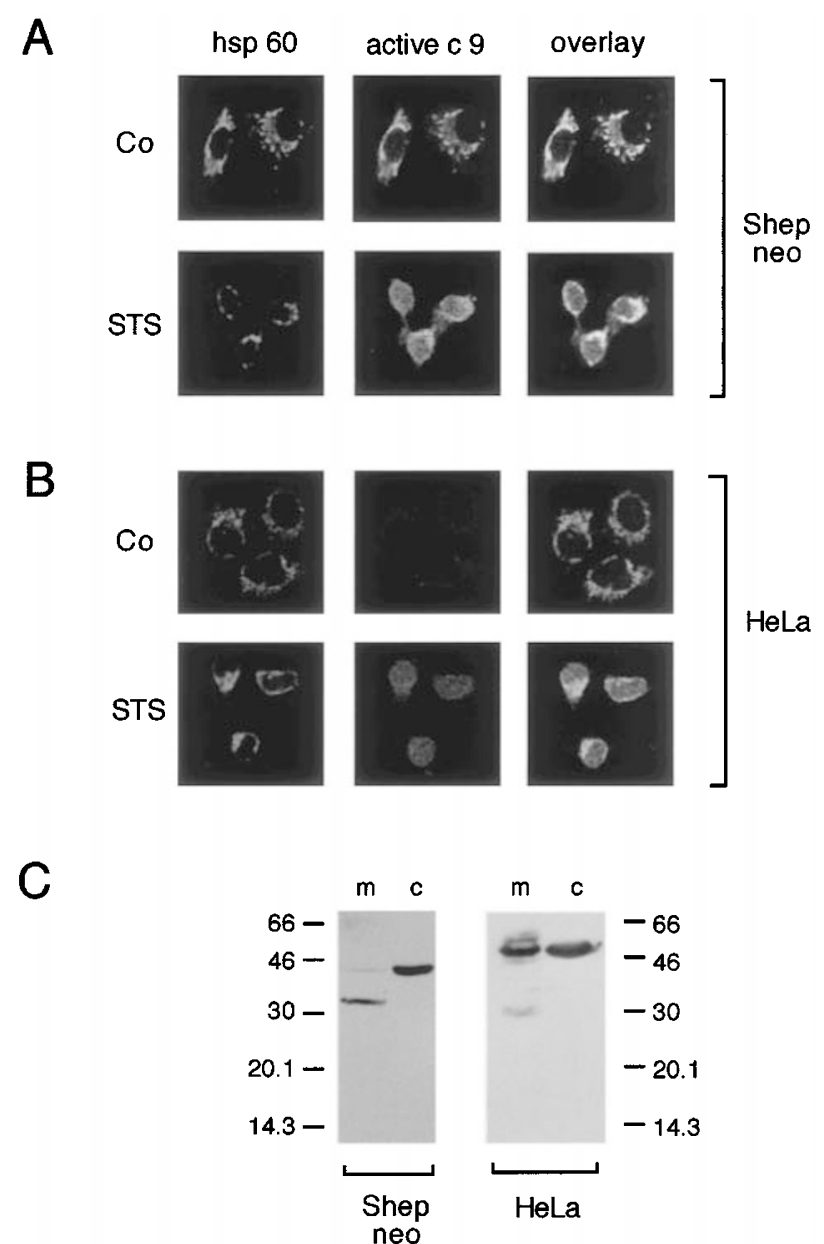

Figure 3 Subcellular compartimentalization of pre-processed caspase-9 in two different cell lines. Shep $(\mathbf{A})$ or HeLa cells $(\mathbf{B})$ were left either untreated or were cultured in the presence of staurosporine, STS (Shep: $1 \mu \mathrm{M}, 2 \mathrm{~h}$; HeLa: $2 \mu \mathrm{M}, 8 \mathrm{~h})$, fixed, and stained to determine the subcellular distribution of hsp60 and pre-processed caspase- 9 by confocal scanning immunofluorescence $(\mathbf{A}, \mathbf{B})$. Untreated cells were subjected to subcellular fractionation to obtain mitochondria $(\mathrm{m})$ or cytosols $(\mathrm{c})$, followed by immunoblotting with a monoclonal antibody that recognizes both pro-caspase- 9 and processed caspase-9 (C)

procaspase-9 would bind to Apaf-1 and would be activated by processing in the presence of cytochrome $c$ and dATP. Here we show that pre-processed caspase-9 may be contained to a variable extent in mitochondria from cells derived from primary organs (Figure 1) as well as in some cell lines (Figures 3, 4). The mechanism for this preprocessing of caspase- 9 is unknown. Whether an activation mechanism similar to that of cytosolic procaspase- 9 exists also for mitochondrial procaspase- 9 is still unclear. Thus far, Apaf-1 has never been detected in the mitochondrial fraction. It could be that procaspase- 9 might undergo processing/activation within mitochondria without the formation of an apoptosome complex. We have attempted to perform mitochondrial import assays with in vitro translated cDNA corresponding to caspase-9, without success, in conditions in which for instance AIF was correctly imported 
active $\mathrm{c} 9$
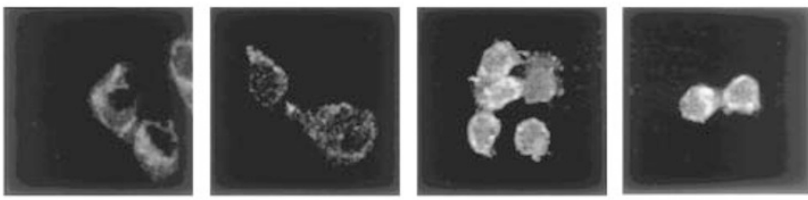

Hoechst
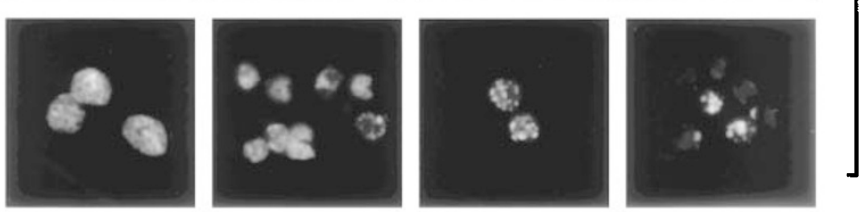

Shep

neo

B

active $\mathrm{c} 9$
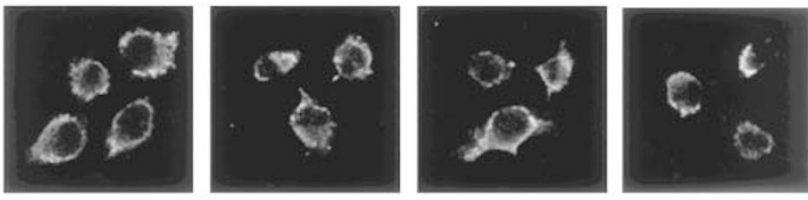

Hoechst
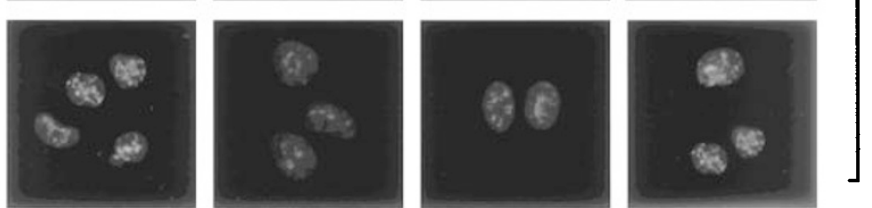

Shep

$\mathrm{Bcl}-2$

Figure 4 Bcl-2-mediated inhibition of the mitochondrio-cytosolic and mitochondrio-nuclear translocation of caspase 9. Neo- and Bcl-2 Shep cells were left either untreated or cultured in the presence of $1 \mu \mathrm{M} \mathrm{STS}$, fixed at the indicated times, and stained with the antibody specific for processed caspase-9 or with Hoechst 33342 to assess nuclear chromatin condensation

into mouse liver mitochondria. ${ }^{27}$ This suggests that import of caspase-9 into mitochondria (and its subsequent processing) does not rely on the classical import pathway. It appears that the pre-processed caspase- 9 naturally present in purified mitochondria possesses an intrinsic activity (Figure 2B,C), which can be stimulated by opening of the PT pore, a manipulation which releases the pre-processed enzyme into the mitochondrial supernatant. This activation is discrete, by a factor of approximately 2 . At present, we do not know whether this reflects an increased substrate accessibility and/or the dilution of a low-affinity inhibitor of caspase-9 contained in the mitochondrial intermembrane space. Thus far, we have failed to detect such a hypothetical inhibitor among concentrated mitochondrial intermembrane proteins.

As mentioned in the Introduction, caspase- 9 activation relies to a low extent on proteolytic activation and is mainly achieved by interaction with the Apaf-1/cytochrome $c$ complex formed in the presence of ATP. Accordingly, mutants of caspase- 9 which cannot be processed can still be enzymatically activated by cytosolic factors such as the Apaf-1/cytochrome $c$ complex. ${ }^{19}$ In conditions in which processed caspase- 9 is secluded behind the outer mitochondrial membrane (and thus separated from Apaf1 , a cytosolic protein), it is thus likely to be relatively inactive. Bcl-2, as shown here (Figure 4), fully prevents the translocation of pre-processed caspase-9 from mitochondria. This may be an additional mechanism by which the control of mitochondrial membrane permeabilization regulates caspase activation and consequent cell death.

\section{Materials and Methods}

\section{Cell lines and apoptosis induction}

Human neuroblastoma Shep cells stably transfected with the human $\mathrm{Bcl}-2$ gene or a neomycin (Neo) resistance vector only, ${ }^{28}$ human cervix carcinoma HeLa cells and mouse embryonic fibroblasts (MEF) from caspase- $3^{-1-29}$ or control mice were cultured in RPMI 1640 (Shep) or DMEM (HeLa and MEF) medium, supplemented with $2 \mathrm{mM}$ L-glutamine, $10 \%$ decomplemented FCS, $1 \mathrm{mM}$ sodium pyruvate, $10 \mathrm{mM}$ Hepes, and $100 \mathrm{U} / \mathrm{ml}$ penicillin/streptomycin. Cell death was induced by addition of $1 \mu \mathrm{M}$ (Shep) or $2 \mu \mathrm{M}$ (HeLa) staurosporine (Sigma).

\section{Purification of mitochondria and assessment of permeability transition}

Female Balb/c mice (4-12 week-old) were killed by cervical dislocation, and organs were removed immediately and placed into ice-cold homogenization buffer $(300 \mathrm{mM}$ saccharose, $5 \mathrm{mM}$ TES, $200 \mu \mathrm{M}$ EGTA, pH 7.2), followed by purification of mitochondria according to standard protocols. ${ }^{26}$ For measurements of MPT opening, liver mitochondria were resuspended in $0.2 \mathrm{M}$ saccharose, $10 \mathrm{mM}$ Tris-MOPS, pH 7.4, $5 \mathrm{mM}$ succinate-Tris, $1 \mathrm{mM} \mathrm{Pi}, 2 \mu \mathrm{M}$ rotenone and $10 \mu \mathrm{M}$ EGTA-Tris. PT opening was monitored as the change of $90^{\circ}$ light scattering at $545 \mathrm{~nm}$ using a Hitachi F-4500 fluorescence spectrophotometer.

\section{Subcellular fractionation}

$90 \times 10^{6}$ control or STS-treated cells were collected by trypsination and centrifugation, washed once in PBS and homogenized with a 
potter Thomas in $5 \mathrm{ml}$ of ice-cold hypotonic buffer $(0.15 \mathrm{mM} \mathrm{MgCl}$, $10 \mathrm{mM} \mathrm{KCl}$ and $10 \mathrm{mM}$ Tris- $\mathrm{HCl}, \mathrm{pH} 7.6$, supplemented with the protease inhibitors antipain, leupeptin and pepstatin at $1 \mu \mathrm{g} \times \mathrm{ml}^{-1}$ ). When intact mitochondria were required, an equal volume of $2 X$ mitochondria homogenization buffer was added before pottering. The cell lysates were centrifugated $\left(3 \mathrm{~min}, 900 \times \mathrm{g}, 4^{\circ} \mathrm{C}\right)$ to remove nuclei and unbroken cells and the supernatants were centrifugated again (10 $\mathrm{min}, 10000 \times g, 4^{\circ} \mathrm{C}$ ) to recover the mitochondrial pellet. The supernatants were further centrifuged ( $15 \mathrm{~min}, 15000 \times \mathrm{g}, 4^{\circ} \mathrm{C}$ ) to obtain cytosol fractions.

\section{Immunoblots}

Samples were prepared in Laemmli buffer as described in the figure legends and separated by SDS-PAGE (12\% acrylamide-0.3\% bisacrylamide, $100 \mu \mathrm{g} /$ lane), followed by Western blotting on nitrocellulose membranes and immunodetection of caspase 9 (mouse monoclonal antibody; clone 5B4, dilution 1:1000, from MBL, Medical \& Biological Laboratories Co., LTD), processed caspase 9 (polyclonal antibody from NEB, dilution 1:500, New England Biotechnology), caspase 3 (rabbit polyclonal antibody, dilution 1:1000, PharMingen), AIF (rabbit antiserum generated against a mixture of three peptides derived from the mouse AIF amino acid sequence, dilution $1: 1000)^{30}$ or cytochrome $c$ (mouse monoclonal antibody, dilution 1:1000, PharMingen). Then, membranes were incubated with anti-mouse or anti-rabbit IgG-horseradish peroxidase conjugate (dilution 1:5000, Southern Biotechnology). Antibody-conjugated activity was visualized using the SuperSignal chemiluminescence reagent (Pierce).

\section{Assessment of caspase activity}

$250 \mathrm{mg}$ of intact mitochondria from mouse liver and caspase $3^{-1-}$ or wild type MEFs cells and 5 units of recombinant, cleaved caspase- 9 (kindly provided by Dr. Guy Salvesen, The Burnham Institute, La Jolla, $\mathrm{CA}$ ) were incubated as described in the figure legends with $100 \mu \mathrm{M} Z$ VAD.afc or Z-LEHD.afc (from Enzyme Systems Products), followed by fluorimetric analysis (excitation: $400 \mathrm{~nm}$; emission: $490 \mathrm{~nm}$ ) using a Hitachi F-4500 fluorescence spectrophotometer.

\section{Immunofluorescence}

After exposure to STS, cells were washed and fixed with $4 \%$ paraformaldehyde, $0.19 \%$ picric acid in PBS $(\mathrm{pH} 7.4)$ for $1 \mathrm{~h}$ at room temperature (RT). Fixed cells were permeabilized with $0.1 \%$ SDS in PBS at RT for 10 min, blocked with $2 \%$ FCS, stained with a polyclonal antibody which detects only cleaved $35 \mathrm{kDa}$ caspase-9 (New England Biolabs, Inc.) and with a monoclonal antibody against heat shock protein (Hsp) 60 (mAb H4149, Sigma-Aldrich), and revealed with a goat anti-rabbit IgG-FITC conjugate and with a goat anti-mouse $\operatorname{lgG}_{1}$ $\mathrm{PE}$ conjugate (Southern Biotechnology). Confocal microscopy was performed on a LEICA TC-SP equipped with an ArKr laser mounted on an inverted LEICA DM IFBE microscope with an $63 \times 1.32$ numerical aperture oil objective. Nuclear apoptosis were detected with Hoechst $33342\left(2 \mu \mathrm{M}\right.$, Sigma, $\left.30 \mathrm{~min}, 37^{\circ} \mathrm{C}\right)$ and visualized by conventional fluorescence microscopy. ${ }^{31}$

\section{Acknowledgements}

We thank Dr. Klaus Michael Debatin (University of Ulm, Germany) for Bcl2-transfected SHEP cells. This work has been supported by a special grant from the Ligue Nationale contre le Cancer, Comité Val de Marne de la Ligue contre le Cancer, as well as grants from ANRS, FRM, and the European Commission QL61-1999-00739 (to G Kroemer). P Costantini received a fellowship from FRM, J-M Bruey from Ligue Nationale Contre la Cancer (comité de Côle d'Or).

\section{References}

1. Nicholson DW (1999) Caspase structure, proteolytic substrates, and function during apoptotic cell death. Cell Death Differ. 6: 1028-1042

2. Zamzami N, Marchetti $P$, Castedo $M$, Zanin $C$, Vayssière J-L, Petit PX and Kroemer G (1995) Reduction in mitochondrial potential constitutes an early irreversible step of programmed lymphocyte death in vivo. J. Exp. Med. 181: $1661-1672$

3. Fletcher GC, Xue L, Passingham SK and Tolkovsky AM (2000) Death commitment is advanced by axotomy in sympathetic neurons. J. Cell. Biol. 150: $741-754$

4. Liu XS, Kim CN, Yang J, Jemmerson R and Wang X (1996) Induction of apoptotic program in cell-free extracts: requirement for dATP and cytochrome C. Cell 86: $147-157$

5. Budijardjo I, Oliver H, Lutter M, Luo X and Wang X (1999) Biochemical pathways of caspase activation during apoptosis. Annu. Rev. Cell. Dev. Biol. 15:269-290

6. Samali A, Cai J, Zhivotovsky B, Jones DP and Orrenius S (1999) Presence of a pre-apoptotic complex of pro-caspase- $3, \mathrm{hsp} 60$, and hsp 10 in the mitochondrial fraction of Jurkat cells. EMBO J. 18: 2040-2048

7. Du C, Fang M, Li Y, Li L and Wang X (2000) Smac, a mitochondrial protein that promotes cytochrome $c$-dependent caspase activation by eliminating IAP inhibition. Cell 102: 33-42

8. Verhagen AM, Ekert PG, Pakusch M, Silke J, Connolly LM, Reid GE, Moritz RL, Simpson RJ and Vaux DL (2000) Identification of DIABLO, a mammalian protein that promotes apoptosis by binding to and antagonizing IAP proteins. Cell 102: $43-53$

9. Krammer PH (2000) CD95's deadly mission in the immune system. Nature 407: $789-795$

10. Sprick MR, Weigand MA, Rieser E, Rauch CT, Juo P, Blenis J, Krammer PH and Walczak $H$ (2001) FADD/MORT1 and caspase-8 are recruited to TRAIL receptors 1 and 2 and are essential for apoptosis mediated by TRAIL receptor 2 . Immunity 12: 599-609

11. Kischkel FC, Lawrence DA, Chuntharapai A, Schow P, Kim KJ and Ashkenazi A (2000) Apo2L/TRAIL-dependent recruitment of endogenous FADD and caspase- 8 to death receptors 4 and 5 . Immunity 12: 611-620

12. Mancini M, Machamer CE, Roy S, Nicholson DW, Thornberry NA, CasciolaRosen LA and Rosen A (2001) Caspase-2 is localized at the Golgi complex and cleaves golgin-160 during apoptosis. J. Cell. Biol. 149: 603-612

13. Nakagawa T, Zhu H, Morishima N, Li E, Xu J, Yankner BA and Yuan J (2000) Caspase-12 mediates endoplasmic reticulum-specific apoptosis and cytotoxicity by amyloid-beta. Nature 403: $98-103$

14. Susin SA, Lorenzo HK, Zamzami N, Marzo I, Larochette N, Alzari PM and Kroemer G (1999) Mitochondrial release of caspases-2 and -9 during the apoptotic process. J. Exp. Med. 189: 381-394

15. Mancini M, Nicholson DW, Roy S, Thornberry NA, Petersen EP, Casciola-Rosen LA and Rosen A (1998) The caspase-3 precursor has a cytosolic and mitochondrial distribution: Implications for apoptotic signaling. J. Cell. Biol. 140: $1485-1495$

16. Quin ZH, Wang Y, Kikly KK, Sapp E, Kegel KB, Aronin N and DiFiglia M (2001) Pro-caspase-8 is predominantly localized in mitochondria and released into cytoplasm upon apoptotic stimulation. J. Biol. Chem. 276: 8079-8086

17. Krajewski S, Krajewska M, Ellerby LM, Welsh K, Xie ZH, Deveraux QL, Salvesen GS, Bredesen DE, Rosenthal RE, Fiskum G and Reed JC (1999) Release of caspase-9 from mitochondria during neuronal apoptosis and cerebral ischemia. Proc. Natl. Acad. Sci. U.S.A. 96: 5752-5757

18. Kroemer G and Reed JC (2000) Mitochondrial control of cell death. Nat Med 6 : $513-519$

19. Stennicke HR, Deveraux QL, Humke EW, Reed JC, Dixit VM and Salvesen GS (1999) Caspase-9 can be activated without proteolytic processing. J. Biol. Chem 274: 8359-8362 
20. Hakem R, Hakem A, Dunca GS, Henderson JT, Woo M, Soengas MS, Elia A, delaPompa JL, Kagi D, Khoo W, Potter J, Yoshida R, Kaufman SA, Lowe SW, Penninger JM and Mak TW (1998) Differential requirement for caspase 9 in apoptotic pathways in vivo. Cell 94: 339-352

21. Kuida K, Haydar TF, Kuan CV, Gu Y, Taya C, Karasuyama H, Su MSS, Rakic P and Plavell RA (1998) Reduced apoptosis and cytochrome c-mediated caspase activation in mice lacking caspase 9. Cell 94: 325-337

22. Soengas MS, Alarcon RM, Yoshida H, Giacca AJ, Hakem R, Mak TW and Lowe SW (1999) Apaf-1 and caspase-9 in p53-dependent apoptosis and tumor inhibition. Science 284: 156-159

23. Srinivasula SM, Ahmed M, Guo Y, Zhan Y, Lazebnik Y, Fernandes-Alnemri Tand Alnemri ES (1999) Identification of an endogenous dominant-negative short isoform of caspase-9 that can regulate apoptosis. Cancer Res. 59: 999-1002

24. Perkins CL, Fang G, Kim CN and Bhalla KN (2000) The role of APfa-1, caspase-9, and bid proteins in etoposide-or paclitaxel-induced mitochondrial events during apoptosis. Cancer Res. 60: 1645-1653

25. Seol DW and Billiar TR (1999) A caspase-9 variant missing the catalytic site is an endogenous inhibitor of apoptosis. J. Biol. Chem. 274: 2072-2076

26. Susin SA, Larochette N, Geuskens M and Kroemer G (2000) Purification of mitochondria for apoptosis assays. Meth. Enzymol. 322: 205-208
27. Susin SA, Lorenzo HK, Zamzami N, Marzo I, Snow BE, Brothers GM, Mangion J, Jacotot E, Costantini P, Loeffler M, Larochette N, Goodlett DR, Aebersold R, Siderovski DP, Penninger JM and Kroemer G (1999) Molecular characterization of mitochondrial apoptosis-inducing factor. Nature 397: 441-446

28. Fulda S, Susin SA, Kroemer G and Debatin KM (1998) Molecular ordering of apoptosis induced by anti-cancer drugs in neuroblastoma cells. Cancer Res. 58: $4453-4460$

29. Woo M, Hakem R, Soengas MS, Ducan GS, Shahinian A, Kägi D, Hakem A, McCurrach M, Khoo W, Kaufman SA, Senaldi G, Howard T, Lowe SW and Mak TW (1998) Essential contribution of caspase 3/CPP32 to apoptosis and its associated nuclear changes. Genes Dev. 12: 806-819

30. Daugas E, Nochy D, Ravagnan L, Loeffler M, Susin SA, Zamzami Nand Kroemer $G$ (2000) Apoptosis inducing factor: an ubiquitous mitochondrial oxidoreductase involved in apoptosis regulation. FEBS Lett. 476: 118-123

31. Ferri KF, Jacotot E, Blanco J, Esté JA, Zamzami A, Susin SA, Brothers G, Reed $J C$, Penninger HM and Kroemer G (2000) Apoptosis control in syncytia induced by the HIV-1-envelope glycoprotein complex. Role of mitochondria and caspases. J. Exp. Med. 192: 1081-1092 